\title{
Laboreal
}

Volume $6 \mathbf{N}^{\circ} 1$ | 2010

Varia

\section{Introducción al texto "Taylorismo, Racionalización, Selección, Orientación” de Henri Wallon}

Introdução ao texto "Taylorismo, Racionalização, Selecção, Orientação" de Henri Wallon

Introduction au texte "Taylorisme, rationalisation, sélection, orientation" de Henri Wallon

Introduction to the text "Taylorism, rationalization, selection, orientation" by Henri Wallon

\section{Régis Ouvrier-Bonnaz}

\section{OpenEdition}

\section{Journals}

Edición electrónica

URL: http://journals.openedition.org/laboreal/9206

DOI: $10.4000 /$ laboreal.9206

ISSN: 1646-5237

\section{Editor}

Universidade do Porto

Referencia electrónica

Régis Ouvrier-Bonnaz, « Introducción al texto "Taylorismo, Racionalización, Selección, Orientación" de Henri Wallon », Laboreal [En línea], Volume 6 Nº1 | 2010, Publicado el 01 julio 2010, consultado el 23 septiembre 2020. URL : http://journals.openedition.org/laboreal/9206 ; DOI : https://doi.org/10.4000/ laboreal.9206

Este documento fue generado automáticamente el 23 septiembre 2020

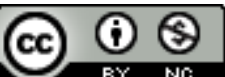

Laboreal está licenciado com uma Licença Creative Commons - Atribuição-NãoComercial 4.0 Internacional. 


\title{
Introducción al texto "Taylorismo, Racionalización, Selección, Orientación" de Henri Wallon
}

\author{
Introdução ao texto "Taylorismo, Racionalização, Selecção, Orientação" de Henri \\ Wallon \\ Introduction au texte "Taylorisme, rationalisation, sélection, orientation" de \\ Henri Wallon \\ Introduction to the text "Taylorism, rationalization, selection, orientation" by \\ Henri Wallon
}

Régis Ouvrier-Bonnaz

\section{REFERENCIA}

Articulo original : Wallon, H. (1947). Taylorisme, rationalisation, sélection, orientation. Technique, Art, Science. Octobre, 5-7.

La presentación de un texto de Wallon (1879 - 1962) en una revista consagrada al estudio y al análisis del trabajo puede sorprender. De hecho, el autor, filósofo, médico y psicólogo, es conocido sobre todo por sus contribuciones a la psicología infantil [1]. Si bien los textos de Wallon sobre el trabajo son raros, su participación en el desarrollo de la psicología del trabajo en Francia, como disciplina independiente, fue determinante, tal como lo demuestra la edición de su libro "Principes de psychologie appliquée" en 1930. Desde la primera línea de esta obra, que hace del estudio del trabajo una cuestión esencial para la psicología, le da una definición al trabajo que se mantiene como referente para los psicólogos del área sosteniendo que :

"el trabajo es una actividad forzada. Ya no es la simple respuesta del organismo al estímulo del momento, ni las del sujeto a las demandas del instinto. Su objeto permanece ajeno a nuestras necesidades, por lo menos a 
las inmediatas, y consiste en la realización de tareas que no se relacionan necesariamente con el juego espontáneo de las funciones psíquicas o mentales. Es su grado creciente de especialización y abstracción que torna urgente la regulación de la ejecución de acuerdo con las posibilidades biológicas o psíquicas del individuo" (traducción libre p. 11).

2 En un homenaje realizado al autor en 1964, Friedman (1902-1977), fundador junto a Naville (1904-1993) de la sociología del trabajo en Francia, marca la importancia de esta última observación relacionada con el aumento de grado de abstracción que se le pide a los trabajadores. En una época en que la introducción de técnicas de automatización tiende a dar un mayor control e intervención a los trabajadores, llama la atención el riesgo que podría conllevar organizar, por parte de los especialistas de producción, los puestos de trabajo desde un punto de vista exclusivamente técnico, sin tener en cuenta los esfuerzos del trabajador para adaptarse motora y mentalmente. Friedman recuerda el punto de vista de Wallon (1930, p.50, traducción libre) según el cual "lo que es construido por el hombre sobre el propio hombre" es difícilmente regulable. Para Wallon, la psicología aplicada no es la aplicación de una psicología que pretende ser teórica o racional, sino su misma negación :

"partiendo de casos concretos y problemas útiles, la psicología aplicada comienza por mostrar el vacío de las antinomias que las psicologías de la introspección y de la intuición plantean entre el mundo interior o de la conciencia y el mundo exterior, entre el hecho psíquico y el número, entre el sujeto puramente abstracto que proponen y el sujeto vivo" (ídem, p.7, traducción libre).

Para Lucien Febvre (1878-1956), a quien se dedica el libro, historiador y co-fundador de la escuela francesa de Annales, que marcó durante mucho tiempo la forma de hacer de numerosos historiadores del Siglo XX, en particular de aquellos que se interesaron por la historia de las técnicas; este libro tuvo como resultado, al estudiar particularmente la actividad que realiza el hombre y al estudiar las relaciones multiformes que mantiene con el exterior, el de "sujetar la psicología tradicional a un cambio entero y radical" (1931, p. 261). El análisis del Taylorismo, retomado en el texto de 1947, se encuentra desarrollado en la tercera parte de este libro del que los dos primeros capítulos - "Racionalización" y "Selección y Orientación Profesional" - conforman el título de este artículo.

4 Este artículo publicado en la revista "Technique, Art, Science", la cual se funda al final de la II Guerra Mundial (1940-1945) por la Direction des Enseignements Techniques del Ministère de l'Education Nationale, para asentar el "Humanismo Técnico", característico del sistema de educación profesional francés. Al finalizar la Guerra, el papel de Wallon en el campo científico y político resultó determinante. Después de haber sido el primer Secretario General de la Comisión de Educación, resultante del Conseil de la Resístanse, presidió la Comisión para la Reforma de la Educación, conocida como el "Plan Langevin-Wallon", cuyas conclusiones se comunicaron a la Asamblea Nacional. En el núcleo de las preocupaciones inmediatas después de la Guerra se encontraba la recuperación económica de Francia. En el marco del esfuerzo para la reconstrucción del país, el mundo laboral se vio confrontado con problemas inéditos y con exigencias contradictorias. De esta forma el Taylorismo, que había sido objeto de numerosas críticas en Francia, se impuso progresivamente, vistiéndose con la ropa más moderna del Fordismo que favorece la articulación de la regulación del control de la 
producción con las regulaciones de los colectivos de trabajo, permitiendo que los empleados tuvieran acceso a una parte de los frutos de la productividad. Es en este contexto que Wallon fija su posición. Para él, el lanzamiento del libro de Taylor (1911) "Principes d'organisation scientifique des usines" marcó un momento histórico ya que es el "el indicio de las profundas transformaciones que atravesaban las relaciones entre el hombre y la técnica” (p. 5, traducción libre).

Wallon señala el antecedente de los trabajos de Adam Smith (1776) cuyo ejemplo de la fabricación de alfileres descrito en 18 operaciones distintas, incluido en "Recherches sur la nature et les causes de la richesse des nations", permanece como modelo de racionalización del trabajo y de selección profesional (libro 1, p. 12). Especifica, de la misma manera, la intención que se encuentra en la base de "los principios de Taylor" a partir de su análisis del corte de metales :

"la innovación, que Taylor consideraba de forma plenamente natural y de una evidencia innegable, consiste en extender a los gestos del hombre las mismas preocupaciones de precisión y de economía que en el uso de la máquina. A cualquier tipo de actividad se le deben corresponder determinados movimientos particularmente bien adaptados que hay que reconocer, seleccionar, enseñar, imponer [...], incluso el trabajo más sencillo no puede escapar de esta ley" (p. 5, traducción libre).

6 El ejemplo del levantamiento de bloques de hierro fundido ilustra esta observación. Para Taylor,

"la ciencia del transporte de hierro fundido es tan complicada que es imposible que un hombre con gran experiencia en este trabajo pueda comprender sus principios e, incluso si los comprendiese, de aplicarlos sin ayuda de un hombre más instruido que él" (1911, p. 56).

7 Taylor reconoce la complejidad del trabajo y la dificultad en su comprensión. Propone, entonces, remover la opacidad del trabajo y hacerlo visible para comprender lo que hacen los trabajadores en su actividad. Su objetivo es el de quitar de la cabeza y de las manos de los trabajadores su saber-hacer y sus habilidades para transferir este saber a la oficina de métodos, donde los especialistas los racionalizarían. Para Taylor, el pensamiento complica las cosas, por eso propone a los trabajadores que liberarse del pensamiento en la acción para simplificarles la vida. La solución que Taylor trae a la organización científica del trabajo se inscribe en una perspectiva productivista, según la cuál el aumento del desempeño conduce a una mejora en los factores de satisfacción de los trabajadores. Hay un tiempo para sufrir y un tiempo para disfrutar de los frutos del trabajo: aquel que produce más es el que más gana. En la realidad, el control del proceso de trabajo, pretendido por Taylor, pretende retirar el dominio de los trabajadores de los tiempos de producción. Los principios Tayloristas de organización tienen como objetivo el de favorecer la sumisión del proceso de trabajo al proceso de valorización del capital. "Definitivamente, Taylor considera al hombre como una simple maquina que debe utilizarse tan económicamente como sea posible" (p. 6, traducción libre).

8 Para Wallon, la innovación que Taylor "consideraba, de forma plenamente natural y de una evidencia innegable, es extender a los gestos del hombre las mismas preocupaciones de precisión y de economía que en el uso de la máquina" (p. 6, traducción libre). A él se le debe dar el crédito de haber sacado de la sombra las 
necesidades que se ignoraba que existiesen, así como sentar los orígenes de la racionalización del trabajo, de la selección y de la orientación profesional. De hecho, el Taylorismo hizo que "la intervención de la psicología (fuese) más urgente, dado que no la reconoció, de manera particular" (1930, p. 13, traducción libre).

Sin embargo, al considerar los movimientos como mecanismos operatorios por analogía a los de una máquina, para eliminar todos los movimientos parásitos e imponer una candencia por debajo de la cual no se podía funcionar, desconocía directamente al hombre. Esto condujo a que Wallon que sostuviera que así: "Como desconoció la fisiología del hombre, también desconoció su psicología" (p. 6). Subraya que, por el "carácter grosero de estos procedimientos, muchas veces contrarios a la naturaleza fisiológicas y psíquicas del hombre, el Taylorismo marcó las dificultades y las reacciones que fueron el punto de partida de importantes progresos. Este, finalmente, contribuyendo para imponer aquello a lo que tenia tendencia a desconocer o eliminar" (p. 7, traducción libre).

10 Wallon reconoce los fundamentos de la intención de Taylor en relación al análisis del trabajo obrero, pero denuncia sus límites. Debido a razones de utilidad vinculadas al rendimiento, buscando aislar elementos básicos de los movimientos de trabajo, Taylor se quedó en la superficie. Preocupado en conectar el análisis del trabajo y la orientación vocacional, Wallon esclarece su crítica al decir que "tan indiferente, tan hostil a las necesidades de la persona humana, el Taylorismo no podía descubrir la orientación profesional, que se opone a la selección como el punto de vista del individuo puede oponerse a las exigencias únicas de una tarea determinada" (p. 7, traducción libre). Desde 1932, en una conferencia pronunciada en el Primer Congreso Mundial de l'Education Nouvelle, "Culture générale et orientation professionnelle", Wallon precisó su oposición: el sistema Taylorista, en vez de dejar al hombre actuar, "disocia la actividad al pedirle únicamente un determinado gesto artificial o una vigilancia uniforme y sin gestos" (1932/1976, p. 209). Tal como sostiene Clot, comentando la crítica de Wallon, "de cierta manera, Taylor no exige de más a los trabajadores, sino de menos. Al seleccionar el tipo movimiento que requiere la menor intervención posible, priva al hombre de su iniciativa" (2006, p.313). La actividad del trabajador no absorberse en su totalidad en operaciones elementales fragmentadas. Wallon analizó bien este fenómeno cuando planteó que "privar al hombre de su iniciativa, amputarlo de su iniciativa durante la jornada laboral, durante sus ocho o diez horas de trabajo, desemboca al esfuerzo más fragmentado, más fatigante, lo más agotador que se pueda encontrar" (1932/1976, p. 209-210).

Desde luego, al hombre se le exige una renuncia que

\footnotetext{
"lo amputa de una gran parte de sus posibilidades, que dejan en el silencio a una serie de actividades necesarias, de movimientos que son necesarios porque constituyen una especie de todo orgánico con los gestos exigidos. Pero esta tensión en la que no se pueden gastar movimientos, conlleva trastornos, disociaciones que estropean la maquinaria humana" (ídem, p. 210, traducción libre).
}

Esta diferenciación entre gesto y movimiento, señalada tempranamente por Wallon, es un avance importante para el análisis del trabajo. Fernández (2003, p. 163-171) lo mostró muy bien al hacer referencia a la definición de actividad de Leóntiev (1984) : el movimiento, el gesto y automatismo son tres aspectos de una misma realidad. Un mismo movimiento, por ejemplo, un movimiento de prensión ; puede dar lugar a gestos 
diferentes, que todos lo realizan. El formateo excesivo de un gesto puede llevar, como consecuencia, a una alteración de la "velocidad del movimiento" [2], afectando al conjunto de relaciones del trabajador con su entorno. Esta calibración del gesto, que influencia el proceso productivo, produce un resultado inverso al deseado, bloqueando la automatización de gestos eficaces al momento de la ejecución, elemento que Leplat (2005) reconoce como una ventaja relacionada con el menor gasto cognitivo.

La demostración de Wallon resultó convincente, la actividad impedida no es abolida, sino que resulta parte integrante de la actividad ejercida en una situación. La pertinencia de este análisis se mantuvo en la sombra durante un largo período de tiempo. Para Prot (2004), la psicología del trabajo, debido a ese olvido, se privó durante mucho tiempo de la posibilidad de explicar los efectos de la inhibición sobre el desempeño así como sobre el fracaso en el trabajo, sobre la salud así como sobre la enfermedad. El hecho de que se tomara en cuenta la historia de la crítica de Wallon al Taylorismo, hizo que Clot (1999, p. 119) reconsiderara la definición clásica de la actividad elaborada por la Ergonomía. Agregando a la dupla [tarea prescrita - actividad realizada] un tercer término [lo real en la actividad], define la actividad no solo como aquello que se hace, sino también como aquello que no se hace, aquello que es interrumpido o retrasado, aquello que se hace para no hacer lo que hay que hacer, abriendo así la psicología del trabajo a las nuevas perspectivas de intervención e investigación. En la línea de las reflexiones de Wallon, podemos razonablemente plantear la hipótesis de que las dificultades encontradas por los profesionales en la realización adecuada de su trabajo y en ejercer correctamente su oficio proviene, en parte, del hecho de lo que ellos no pueden hacer en aquello que hacen. Aquí hay materia para pensar las crecientes dificultades encontradas por los profesionales para hacer su trabajo "a pesar de todo", en particular cuando se les imponen las orientaciones impartidas desde "la esfera gerencial", tal como suele ser con mayor frecuencia, de asumir la responsabilidad sin darles responsabilidad real en la definición de su trabajo.

En un momento en que presenciamos la emergencia de una forma de Re-Taylorismo, legitimado bajo la cobertura de la buena práctica determinada por la conminación al compromiso personal y por la transferencia de los estándares de la prescripción de la industria a las empresas de servicio, la contribución de Wallon permanece vigente a todos aquellos que se interesan por el trabajo y por los efectos de su intensificación sobre las personas.

\section{BIBLIOGRAFÍA}

Clot, Y. (1999). La fonction psychologique du travail. Paris : PUF.

Clot, Y. (2006). Une intensification du travail peut-elle en cacher une autre ? In P. Askenasy, D. Carton, F. de Coninck \& M. Gollac (coord.), Organisation et intensité du travail [pp. 313-317]. Toulouse : Octares. 
Febvre, L. (1931). La psychologie appliquée : problèmes de méthode et solutions pratiques. Annales d'histoire économique et sociale, Vol 3, 10, 261-265.

Fernandez, G. (2003). Développement d'un geste de métier. Histoire du freinage en gare du Nord. Thèse pour le doctorat de psychologie sous la direction d'Yves Clot. Paris, CNAM.

Friedmann, G. (1964). In memoriam : Henri Wallon (1879-1962). Sociologie du Travail, 1, 1-7.

Léontiev, A. (1984). Activité, conscience, personnalité. Moscou : Editions du Progrès.

Leplat, J. (2005). Les automatismes dans l'activité : pour une réhabilitation et un bon usage. @ctivités, vol 2, 2, 43-68.

Prot, B. (2004). Controverses entre les professionnels à propos de l'exercice de leur métier source de développement de la santé. Gérontologie et société, 111, 171-181.

Taylor, F.-W. (1911). Principes d'organisation scientifique des usines.

Paris : Dunod et Pinat Editeurs.

Wallon, H. (1930). Principes de psychologie appliquée. Paris : Armand Colin.

Wallon, H. (1932/1976). Culture générale et orientation professionnelle, Pour l'ère nouvelle, 81. Repris dans Lectures d'Henri Wallon. Choix de textes [pp. 205-218]. Paris : Editions sociales.

\section{NOTAS}

1. Ver en este sentido la traducción portuguesa de "La revolución psicológica del niño" (Lisboa : Edições 70, 1978), con introducción de René Zazzo: A evolução psicológica da criança.

2. En francés "l'allure du mouvement". Utilizamos esta expresión como referencia a Canguilhem que habla "d'allure da vida", para definir a la fisiología como la "ciencia de las allures estables en la vida" en "Le normal et le pathologique" (1943/2005, p. 137).

\section{AUTOR}

\section{RÉGIS OUVRIER-BONNAZ}

Groupe de Recherche et d'Etude sur la l'Histoire du Travail et de l'Orientation (GRESHTO), Centre de Recherche sur le Travail et Développement (CRTD) Conservatoire National des Arts et Métiers (CNAM), 41, Rue Gay Lussac 75005 Paris, France regis.ouvrier_bonnaz@cnam.fr 